\title{
Inhaled budesonide and prednisone led to similar rates of asthma relapse after emergency department discharge
}

FitzGerald JM, Shragge D, Haddon J, et al. A randomized, controlled trial of high dose, inhaled budesonide versus oral prednisone in patients discharged from the emergency department following an acute asthma exacerbation. Can Respir J $2000 \mathrm{Jan} / \mathrm{Feb} ; 7: 61-7$.

QUESTION: In patients who are discharged from the emergency department after a severe acute asthma attack, do high doses of prednisone and inhaled budesonide lead to similar rates of asthma relapse?

\section{Design}

Randomised (unclear allocation concealment*), blinded \{clinicians, patients, outcome assessors, and statisticians $\} \nmid, *$ controlled trial with $7-10$ day follow up.

\section{Setting}

3 university affiliated urban emergency departments in Canada.

\section{Patients}

185 patients who were $15-70$ years of age, had an acute asthma exacerbation, were well enough to be discharged (postbronchodilator $\mathrm{FEV}_{1}>50 \%$ of predicted normal rate), and were able to use Turbuhaler correctly. Exclusion criteria included chronic obstructive pulmonary disease, intolerance to systemic glucocorticosteroids, peptic ulcer disease, active tuberculosis, fungal infection, type 1 diabetes mellitus, moderate to severe hypertension, pregnancy, lactation, or no effective contraception use (for women of childbearing age). $82 \%$ of the patients completed the study, and $95 \%$ of the patients (mean age $28 \mathrm{y}, 57 \%$ women) were included in the analysis.

\section{Intervention}

All patients received 1 dose of systemic glucocorticosteroids (intravenous methylprednisolone, $125 \mathrm{mg}$, or oral prednisone, 40-60 mg) before randomisation. Patients were allocated to inhaled budesonide, $2400 \mu \mathrm{g} /$ day given in 3 inhalations of $200 \mu \mathrm{g} 4$ times per day $(\mathrm{n}=90)$, or to prednisone, $40 \mathrm{mg}$ /day given once in the morning $(\mathrm{n}=85)$ for $7-10$ days.

\section{Main outcome measures}

Relapse rate (return to the emergency department). Secondary outcome measures included adverse events and changes from baseline in $\mathrm{FEV}_{1}$, peak expiratory flow, self rated symptom scores, and Asthma Quality of Life scores.

\section{Main results}

Treatment groups had similar relapse rates (table). The study had $80 \%$ power to detect a difference $\geq 10 \%$ at the $5 \%$ level of statistical significance. No differences in secondary outcomes existed between groups.

\section{Conclusion}

In patients discharged from the emergency department after treatment with systemic corticosteroids for severe acute exacerbation of asthma, home use of inhaled budesonide and oral prednisone led to similar rates of relapse.

*See glossary.

†Information provided by author.
Inhaled budesonide $v$ prednisone in patients discharged from the emergency department after a severe acute exacerbation of asthma $\ddagger$

\begin{tabular}{lllll}
$\begin{array}{l}\text { Outcomes at } \\
7 \text { to } 10 \text { days }\end{array}$ & Budesonide & Prednisone & RRR $(95 \%$ Cl) & NNT (Cl) \\
Relapse rate & $10 \%$ & $12 \%$ & $15 \%(-94$ to 63$)$ & Not significant \\
\hline
\end{tabular}

¥Abbreviations defined in glossary; RRR, NNT, and $\mathrm{Cl}$ calculated from data in article.

\section{COMMENTARY}

A particular strength of the study by FitzGerald $e t a l$ is that it had sufficient power to assess whether the 2 interventions led to equivalent relapse rates after discharge. Predefined equivalence limits were established, and sufficient numbers of patients were randomised to test the null hypothesis and show whether a difference in relapse rate existed between groups. 2 factors limit the generalisability of the findings. Firstly, patients who had received a course of oral prednisolone in the month before enrolment were excluded. The influence of such patients who may have had more brittle disease or who may have been at higher risk for relapse cannot be predicted. Therefore, high dose inhaled budesonide cannot be recommended in patients who present with a second exacerbation within a short (1 month) time period. Secondly, only $35 \%$ of patients were receiving any regular inhaled steroid at enrolment.

It is not possible to determine whether patients who have never received inhaled steroids and patients who regularly receive such treatment respond differently in terms of their likelihood of relapse. A subgroup analysis based on previous inhaled steroid use would be inappropriate because the study does not have sufficient power to assess this.

This study provides encouraging evidence that a substantial proportion of adult patients attending the emergency department because of asthma exacerbations can be safely discharged home with a 7-10 day course of high dose inhaled budesonide instead of a 7-10 day course of oral prednisone. However, further studies are required to investigate whether recent or maintenance inhaled steroid use, or both, are important factors in determining response before high dose budesonide can be recommended for all patients discharged from the emergency department after an acute asthma exacerbation.

Nick Adams, MBChB St. George's Hospital Medical School London, UK 